\title{
Reduction of plasma angiopoietin-like 2 after cardiac surgery is related to tissue inflammation and senescence status of patients
}

Pierre-Emmanuel Noly, MD, ${ }^{\mathrm{a}}$ Pauline Labbé, PhD, ${ }^{\mathrm{b}, \mathrm{c}}$ Nathalie Thorin-Trescases, $\mathrm{PhD},{ }^{\mathrm{b}}$

Annik Fortier, MSc, ${ }^{\mathrm{d}}$ Albert Nguyen, $\mathrm{PhD},{ }^{\mathrm{b}}$ Eric Thorin, $\mathrm{PhD},{ }^{\mathrm{a}}$ and Michel Carrier, $\mathrm{MD}^{\mathrm{a}}$

\section{ABSTRACT}

Objectives: A strong relationship between high circulating angiopoietin-like 2 (ANGPTL2) levels, a proinflammatory adipokine, and cardiovascular diseases has been reported. Our objective was to determine whether plasma ANGPTL2 and high-sensitivity C-reactive protein (hs-CRP) levels change postoperatively in patients who underwent heart valve surgery and/or coronary artery bypass grafting. We hypothesized that a corrective cardiac surgery would decrease ANGPTL2 levels.

Methods: In 47 prospectively recruited patients who underwent coronary artery bypass grafting $(\mathrm{n}=16)$, valve replacement $(\mathrm{n}=16)$, or both $(\mathrm{n}=15)$, we measured plasma ANGPTL2 and hs-CRP levels preoperatively, at 24 hours, at 3 to 5 days (hospital discharge), and at 30 to 90 days (follow-up) after surgery. Mediastinal adipose tissue and distal fragments of the left internal mammary artery (IMA) were harvested during surgery and mRNA expression of inflammatory and senescence markers was assessed using real-time quantitative polymerase chain reaction.

Results: ANGPTL2 and hs-CRP levels were elevated 24 hours after surgery and then returned to baseline levels. We noted, however, a dichotomy among patients: compared with baseline, plasma ANGPTL2 levels either significantly decreased $(\mathrm{n}=21 / 47)$ or increased $(\mathrm{n}=26 / 47)$ after surgery. In contrast, hs-CRP levels were identical between groups $(P=.997)$. Patients in the increased group were older $(P=.002)$ with a higher systolic blood pressure $(P=.038)$ at baseline. Moreover, changes in ANGPTL2 levels ( $\triangle$ ANGPTL2 $=$ final minus initial levels) positively correlated with mRNA expression of tumor necrosis factor $\alpha$ and interleukin 8 in mediastinal adipose tissue and IMA $(P<.05)$ and with the senescenceassociated marker cyclin-dependent kinase inhibitor 1 in IMA $(P=.009)$.

Conclusions: In younger patients with lower levels of tissue inflammation and arterial senescence load, ANGPTL2, but not hs-CRP levels decreased after cardiac surgery, suggesting that circulating ANGPTL2 reflects tissue inflammation and senescence. (J Thorac Cardiovasc Surg 2019;158:792-802)

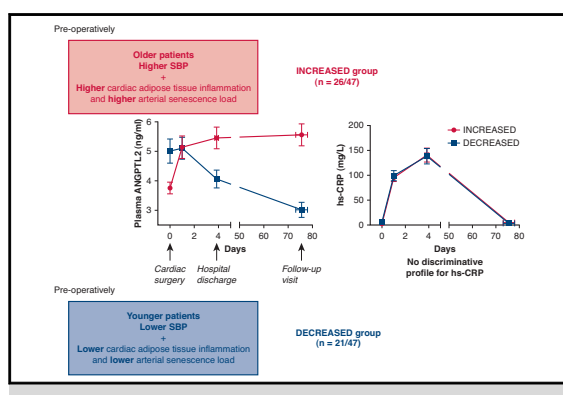

Reduced blood ANGPTL2 post cardiac surgery associates with low inflammation and senescence.

\section{Central Message}

Plasma ANGPTL2, but not hs-CRP, decreased after cardiac surgery in young patients with low tissue inflammation and arterial senescence.

\section{Perspective}

The postoperative cardiovascular outcomes were similar among patients in whom plasma ANGPTL2 either increased or decreased. Further evaluation in a larger population of patients who underwent a cardiac surgery is needed to determine the potential predictive value of such dichotomy on the severity/incidence of long term post surgery cardiovascular events.

See Commentary on page 803 .
Cardiovascular disease (CVD) is the second leading cause of death and affects 2.4 million adults in Canada (www.canada. $\mathrm{ca} / \mathrm{en} /$ public-health). Its most frequent form, coronary artery disease (CAD) is due to age-related atherosclerosis in which chronic vascular inflammation plays a central role in its pathogenesis. ${ }^{1}$ Recently, new markers of systemic low-grade inflammation have been proposed. Among them is angiopoietin-like 2 (ANGPTL2), a proinflammatory
From the ${ }^{\mathrm{a}}$ Faculty of Medicine, Department of Surgery, Montreal Heart Institute, ${ }^{\mathrm{c}}$ Department of Pharmacology, ${ }^{b}$ Montreal Heart Institute Research Center, Université de Montréal, Montreal, Quebec, Canada; and ${ }^{\mathrm{d}}$ Montreal Health Innovations Coordinating Center, Montreal, Quebec, Canada.

This work was funded by grants from the Canadian Institutes of Health Research (MOP 133649; E.T.) and by the Foundation of the Montreal Heart Institute (E.T., M.C.).

Drs Thorin and Carrier are co-senior authors.
Drs Noly and Labbé equally contributed to this work.

Received for publication Aug 17, 2018; revisions received Dec 4, 2018; accepted for publication Dec 15, 2018; available ahead of print Feb 10, 2019.

Address for reprints: Eric Thorin, PhD, Montreal Heart Institute, 5000 Rue Bélanger Est, Montreal, Quebec H1T 1C8, Canada (E-mail: eric.thorin@umontreal.ca). 0022-5223/\$36.00

Copyright () 2019 by The American Association for Thoracic Surgery https://doi.org/10.1016/j.jtcvs.2018.12.047 


$\begin{array}{ll}\text { Abbreviations and Acronyms } \\ \text { AF } & =\text { atrial fibrillation } \\ \text { ANGPTL2 } & =\text { angiopoietin-like } 2 \\ \text { ANOVA } & =\text { analysis of variance } \\ \text { AT } & =\text { adipose tissue } \\ \text { CABG } & =\text { coronary artery bypass grafting } \\ \text { CAD } & =\text { coronary artery disease } \\ \text { CHD } & =\text { coronary heart disease } \\ \text { CPB } & =\text { cardiopulmonary bypass } \\ \text { CVD } & =\text { cardiovascular disease } \\ \text { DBP } & =\text { diastolic blood pressure } \\ \text { HDL } & =\text { high-density lipoprotein } \\ \text { HR } & =\text { heart rate } \\ \text { hs-CRP } & =\text { high-sensitivity C-reactive protein } \\ \text { IL } & =\text { interleukin } \\ \text { IMA } & =\text { internal mammary artery } \\ \text { MAT } & =\text { mediastinal adipose tissue } \\ \text { p21 } & =\text { cyclin-dependent kinase inhibitor } 1 \\ \text { SBP } & =\text { systolic blood pressure } \\ \text { TNF } & =\text { tumor necrosis factor } \\ \text { VR } & =\text { valve replacement or repair }\end{array}$

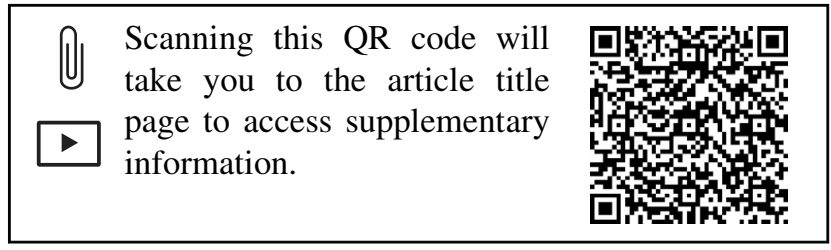

adipokine. ${ }^{2}$ ANGPTL2 is primarily secreted by adipose tissue (AT), but also by senescent human endothelial cells and tissue macrophages. ${ }^{3}$ ANGPTL2 promotes inflammation, endothelial dysfunction, and triggers other pathways independent of inflammation contributing to the initiation and the progression of atherosclerosis. ${ }^{3-6}$ According to the results of a large study in a Japanese population, circulating levels of ANGPTL2 could be a novel risk factor for the development of CVD. ${ }^{4}$ Previous studies reported elevated ANGPTL2 levels in patients with acute coronary syndrome, ${ }^{7-10}$ carotid atherosclerosis, ${ }^{11}$ heart failure, ${ }^{12,13}$ and dilated cardiomyopathy, ${ }^{14}$ making ANGPTL2 a new potential biomarker of heart disease. ${ }^{15}$ Prospective studies also showed a positive association between circulating ANGPTL2 levels and the risk of developing diabetes in the general population ${ }^{16}$ or the probability for a diabetic patient to experience major adverse cardiovascular events or even death. ${ }^{17}$ Therefore, there is a clear relationship between high circulating ANGPTL2 levels and the presence of CVD and its risk factors.

If ANGPTL2 contributes to the development and progression of CVD, could a reduction in ANGPTL2 be beneficial in patients with CVD? Recently, the autocrine/paracrine contribution of cardiomyocyte-derived ANGPTL2 has been shown in cardiac dysfunction and the authors questioned whether circulating ANGPTL2 levels would decrease as cardiac dysfunction improved. ${ }^{14}$ In patients with CAD or heart valve disease but normal cardiac function, the effect of coronary artery bypass grafting (CABG) or valve replacement or repair (VR) on ANGPTL2 levels is not known. We hypothesized that a corrective cardiac surgery would decrease ANGPTL2 levels in these patients, and that a high tissue inflammatory and senescence background would prevent this decrease. Our objectives were: (1) to determine the pattern of the changes in plasma ANGPTL2 levels after cardiac surgery; and (2) establish whether the changes in plasma ANGPTL2 levels correlate with the vascular and AT inflammatory and senescence status of the patient.

\section{METHODS \\ Patients and Study Design}

Forty-seven patients who underwent $(\mathrm{n}=16)$, aortic or mitral VR $(\mathrm{n}=16)$, or both $(\mathrm{n}=15)$ were prospectively included in the study at the Montreal Heart Institute (Quebec, Canada) (Table E1). Patients were prospectively screened and recruited in a consecutive fashion (20 patients in 2014, 22 patients in 2015, and 5 patients in 2016). Inclusion criteria were patients who underwent elective CABG and/or VR with normal left ventricular function at preoperative evaluation. Isolated VR was performed on patients with normal coronary angiography. Patients who underwent other types of procedures were excluded. All patients signed an informed consent and the study (ICM 13-1492) was approved by the Montreal Heart Institute committee for ethical human research. In the overall study population, the mean age was $68 \pm 8$ years and $79 \%$ were male. All patients had at least 1 risk factor for CVD and received preventive treatment such aspirin or a statin before surgery. The basal preoperative characteristics of the patients are detailed in Table 1. All patients underwent cardiac surgery with cardiopulmonary bypass (CPB; Table E1).

For each patient, plasma ANGPTL2 and high-sensitivity C-reactive protein (hs-CRP) levels were measured at 4 time points: the day of the surgery (basal), the day after surgery ( 24 hours), before hospital discharge (3-5 days), and at the clinical follow-up (30-90 days). During surgery, AT from the anterior mediastinum was harvested $\left(1 \mathrm{~cm}^{3}\right)$, frozen using liquid nitrogen, and stored at $-80^{\circ} \mathrm{C}$. In addition, in patients who underwent CABG surgery, a distal segment of left internal mammary artery (IMA) measuring $1 \mathrm{~cm}$ in length was harvested, frozen and stored at $-80^{\circ} \mathrm{C}$. Then, mRNA abundance of ANGPTL2 and other markers of inflammation (transforming growth factor $\beta 1$, tumor necrosis factor $[T N F]-\alpha$, interleukin $[I L]-8, I L-6)$ and senescence (cyclin-dependent kinase inhibitor $1[p 21]$ ) was subsequently measured in these tissues (details are available in the Appendix E1).

\section{Statistical Analysis}

Data are presented as mean \pm standard deviation of $\mathrm{n}$ patients in the text and in the tables, and for clarity as mean \pm standard error of the mean in the figures. Comparison of the change in plasma ANGPTL2 levels over time between surgical procedures was done using a 2-way repeated measures analysis of variance (ANOVA) including the interaction term, Time $\times$ Surgery. Analyses were performed using SAS software version 9.4 (SAS Institute Inc, Cary, NC). The MIXED procedure of the SAS software was used and various models of variance-covariance were tried 
TABLE 1. Preoperative characteristics

\begin{tabular}{|c|c|c|c|c|}
\hline Characteristic & All patients $(n=47)$ & Valve only $(n=16)$ & Valve and CABG $(n=15)$ & $\operatorname{CABG}(n=16)$ \\
\hline Age, y & $68 \pm 8$ & $68 \pm 8$ & $71 \pm 7$ & $65 \pm 8$ \\
\hline Male sex, n (\%) & $37(79)$ & $9(56)$ & $14(93)^{*}$ & $14(88)$ \\
\hline Height, m & $1.69 \pm 0.10$ & $1.67 \pm 0.10$ & $1.67 \pm 0.07$ & $1.73 \pm 0.10$ \\
\hline Weight, $\mathrm{kg}$ & $82.8 \pm 15.0$ & $81.7 \pm 18.9$ & $81.8 \pm 12.1$ & $85.0 \pm 13.9$ \\
\hline BMI & $29.0 \pm 4.8$ & $29.4 \pm 6.2$ & $29.3 \pm 4.3$ & $28.3 \pm 3.8$ \\
\hline \multicolumn{5}{|l|}{ Risk factors } \\
\hline Dyslipidemia & $38(81)$ & $9(56)$ & $13(87)$ & $16(100)^{*}$ \\
\hline Hypertension & $35(75)$ & $8(50)$ & $14(93)^{*}$ & $13(81)$ \\
\hline Obesity & $22(47)$ & $8(50)$ & $8(53)$ & $6(38)$ \\
\hline Diabetes & $18(38)$ & $4(25)$ & $6(40)$ & $8(50)$ \\
\hline Active smoker & $7(15)$ & $3(19)$ & $2(13)$ & $2(12)$ \\
\hline Ex-smoker & $13(28)$ & $3(19)$ & $5(33)$ & $5(31)$ \\
\hline COPD & $5(11)$ & $1(6)$ & $4(27)$ & $0(0)$ \\
\hline Family history of CVD & $14(30)$ & $5(31)$ & $3(20)$ & $5(31)$ \\
\hline \multicolumn{5}{|l|}{ Medical history } \\
\hline Previous MI & $10(21)$ & $0(0)$ & $3(20)$ & $7(44)^{*}$ \\
\hline Acute KD & $4(9)$ & $1(6)$ & $2(13)$ & $1(6)$ \\
\hline \multicolumn{5}{|l|}{ Medication } \\
\hline$\beta$-Blockers & $32(68)$ & $7(44)$ & $11(73)$ & $14(88)^{*}$ \\
\hline ACE inhibitors & $8(17)$ & $3(19)$ & $2(13)$ & $3(29)$ \\
\hline AR antagonists & $10(21)$ & $4(25)$ & $3(20)$ & $3(29)$ \\
\hline Diuretic & $16(34)$ & $5(31)$ & $5(33)$ & $6(38)$ \\
\hline Hypoglycemic agent & $12(26)$ & $3(19)$ & $1(7)$ & $8(50)$ \\
\hline Anticoagulant & $7(15)$ & 3 (19) & $1(7)$ & 3 (19) \\
\hline Aspirin & $43(91)$ & $14(88)$ & $13(87)$ & $16(100)$ \\
\hline Statin & $39(83)$ & $9(56)$ & $14(93)$ & $16(100)^{*}$ \\
\hline \multicolumn{5}{|l|}{ Echography } \\
\hline LVEF, \% & $58.1 \pm 9.8$ & $62.7 \pm 4.4 \dagger$ & $59.3 \pm 5.5$ & $52.3 \pm 13.6$ \\
\hline LVDD, mm & $44.9 \pm 5.9(37)$ & $44.4 \pm 6.0$ & $44.4 \pm 5.5(14)$ & $46.9 \pm 6.6(7)$ \\
\hline LVSD, mm & $27.8 \pm 7.3(35)$ & $25.8 \pm 5.4(15)$ & $28.1 \pm 5.9(14)$ & $32.2 \pm 12.5(6)$ \\
\hline \multicolumn{5}{|l|}{ Hemodynamic } \\
\hline $\mathrm{SBP}, \mathrm{mm} \mathrm{Hg}$ & $130 \pm 18(42)$ & $138 \pm 20(14)$ & $127 \pm 17(12)$ & $125 \pm 16$ \\
\hline $\mathrm{DBP}, \mathrm{mm} \mathrm{Hg}$ & $72 \pm 13(42)$ & $78 \pm 12(14)$ & $72 \pm 17(12)$ & $69 \pm 11$ \\
\hline $\mathrm{HR}$, beats per minute & $76 \pm 13$ & $76 \pm 10$ & $77 \pm 13$ & $75 \pm 15$ \\
\hline \multicolumn{5}{|l|}{ Blood analysis } \\
\hline Total cholesterol, $\mathrm{mmol} / \mathrm{L}$ & $3.4 \pm 1.0$ & $3.8 \pm 1.2$ & $3.2 \pm 0.8$ & $3.2 \pm 1.1$ \\
\hline LDL cholesterol, mmol/L & $1.6 \pm 0.9$ & $1.9 \pm 0.9$ & $1.4 \pm 0.7$ & $1.5 \pm 1.0$ \\
\hline HDL cholesterol, mmol/L & $1.2 \pm 0.3$ & $1.2 \pm 0.3$ & $1.0 \pm 0.3$ & $1.3 \pm 0.4$ \\
\hline Triglycerides, mmol/L & $1.5 \pm 0.7$ & $1.6 \pm 0.7$ & $1.7 \pm 0.9$ & $1.3 \pm 0.5$ \\
\hline HbA1c, $\%$ & $0.061 \pm 0.020$ & $0.055 \pm 0.005$ & $0.060 \pm 0.039(5)$ & $0.066 \pm 0.008(8)$ \\
\hline Creatinine, $\mathrm{mmol} / \mathrm{L}$ & $92.2 \pm 28.1$ & $81.4 \pm 24.8$ & $96.1 \pm 21.6 \ddagger$ & $99.3 \pm 34.4$ \\
\hline $\mathrm{eGFR}, \mathrm{mL} / \mathrm{min} / 1.73 \mathrm{~m}^{2}$ & $81.1 \pm 22.7$ & $85.9 \pm 22.6$ & $74.3 \pm 20.2$ & $82.6 \pm 24.8$ \\
\hline hs-CRP, mg/L & $4.5 \pm 10.6(46)$ & $3.2 \pm 4.3(15)$ & $2.6 \pm 2.3$ & $7.4 \pm 17.4$ \\
\hline ANGPTL2, ng/mL & $4.3 \pm 1.6$ & $4.4 \pm 1.6$ & $4.3 \pm 1.4$ & $4.2 \pm 1.8$ \\
\hline \multicolumn{5}{|l|}{ Cell count, $\times 10^{9} / \mathrm{L}$} \\
\hline Leukocytes & $7.65 \pm 1.76$ & $7.94 \pm 2.16$ & $7.79 \pm 1.94$ & $7.16 \pm 0.82$ \\
\hline Neutrophils & $0.63 \pm 0.08$ & $0.62 \pm 0.10$ & $0.66 \pm 0.08$ & $0.62 \pm 0.06$ \\
\hline Lymphocytes & $0.25 \pm 0.08$ & $0.27 \pm 0.10$ & $0.22 \pm 0.06$ & $0.26 \pm 0.07$ \\
\hline Monocytes & $0.09 \pm 0.02$ & $0.08 \pm 0.02$ & $0.08 \pm 0.03$ & $0.09 \pm 0.02$ \\
\hline Eosinophils & $0.03 \pm 0.02$ & $0.02 \pm 0.03$ & $0.03 \pm 0.02$ & $0.02 \pm 0.01$ \\
\hline Basophils & $0.008 \pm 0.005$ & $0.009 \pm 0.007$ & $0.008 \pm 0.003$ & $0.007 \pm 0.003$ \\
\hline
\end{tabular}


TABLE 1. Continued

\begin{tabular}{|c|c|c|c|c|}
\hline Characteristic & All patients $(n=47)$ & Valve only $(n=16)$ & Valve and CABG $(n=15)$ & CABG $(n=16)$ \\
\hline \multicolumn{5}{|l|}{ Operative parameters } \\
\hline Cardiopulmonary bypass duration, minutes & $74 \pm 24$ & $71 \pm 13$ & $93 \pm 26 \dagger, \ddagger$ & $60 \pm 19$ \\
\hline Aortic clamp duration, minutes & $59 \pm 22$ & $59 \pm 12 \dagger$ & $77 \pm 21 \dagger, \ddagger$ & $43 \pm 18 \ddagger$ \\
\hline
\end{tabular}

Data are presented as mean \pm standard deviation or n $(\%)$. $C A B G$, Coronary artery bypass grafting; $B M I$, body mass index; $C O P D$, chronic obstructive pulmonary disease; $C V D$, cardiovascular diseases; $M I$, myocardial infarction; $K D$, kidney disease; $A C E$, angiotensin-converting enzyme; $A R$, angiotensin II receptor; $L V E F$, left ventricular ejection fraction; $L V D D$, left ventricular diastolic diameter; $L V S D$, left ventricular systolic diameter; $S B P$, systolic blood pressure; $D B P$, diastolic blood pressure; $H R$, heart rate; $L D L$, lowdensity lipoprotein; $H D L$, high-density lipoprotein; HbAlc, glycated hemoglobin A1c; $e G F R$, estimated glomerular filtration rate; hs-CRP, high-sensitivity C-reactive protein; ANGPTL2, angiopoietin-like 2 . $* P<.05$ versus valve $\left(\chi^{2}\right.$ test). $\dagger P<.05$ versus CABG. $\ddagger P<.05$ versus valve ( 1 -way analysis of variance followed by Tukey post hoc test; or Kruskal-Wallis followed by Dunn post hoc test for non-Gaussian distribution).

and tested to take into account the between-within subject variance. The model with the smallest small-sample-size-corrected version of Akaike information criterion was retained. Repeated measures ANOVA models were used to study change of plasma ANGPTL2 levels after cardiac surgery. Oneway model followed by specific contrasts were used to compare ANGPTL2 levels at specific times post surgery. Changes in leukocyte and neutrophil numbers and in hs-CRP levels over time were also studied using 1-way repeated measures ANOVA. To study the relation between ANGPTL2 levels and hs-CRP levels over time, a generalized estimating equation model (with the MIXED procedure of SAS) was used, where time was taken as a continuous variable. The $\triangle$ ANGPTL2, defined as postoperative ANGPTL2 levels measured at the end of the study minus preoperative ANGPTL2 levels, was calculated for each subject. A new dichotomous group variable was created according to the value of this $\Delta$ : subjects with negative values were included in the DECREASED group, whereas subjects with positive values were included in the INCREASED group. Group comparisons of basal preoperative parameters and clinical outcomes were done using 1-way ANOVA and $\chi^{2}$ tests. Comparison of the change in plasma ANGPTL2 levels between these 2 groups was done using a 2-way repeated measures ANOVA. Comparison of the mRNA levels of ANGPTL2, TNF- $\alpha, I L-8, I L-6$, and $p 21$ in mediastinal adipose tissue (MAT) and IMA fragments between these 2 groups was done using a nonparametric Mann-Whitney test. To assess the parameters that influenced $\triangle$ ANGPTL2, correlation analyses and simple linear regression analyses were performed. To further determine which of these parameters were independently related to $\triangle$ ANGPTL2, variables with a $P$ value $<.20$ in a simple model were further examined using multiple linear regression analysis using a backward selection process. Statistical significance was set at a $P$ value $<.05$. No correction or adjustment was used or done for multiple testing.

\section{RESULTS}

\section{Change in Plasma ANGPTL2 Levels After Cardiac Surgery}

The temporal change in ANGPTL2 levels after cardiac surgery was similar among the 3 types of surgery (CABG, $\mathrm{VR}$, and $\mathrm{CABG}$ with VR [CABG+VR]; interaction Type of surgery $\times$ Time; $P=.813$, 2-way ANOVA with repeated measures; Figure E1). Thus, in the present study, the type of surgery had no effect on ANGPTL2 levels. Globally, ANGPTL2 levels increased 24 hours after surgery $(P<.001)$ and then decreased progressively at $3.9 \pm 1.0$ days and $75.6 \pm 17.0$ days $(P<.05$; Figure $1, A)$. The significant rise in ANGPTL2 levels observed 24 hours after the surgery paralleled an increase in the number of leukocytes and neutrophils $(P<.0001$; Figure E2), suggesting a transient inflammatory response induced by the surgery itself and the CPB.

We observed, however, 2 different patterns of change in plasma ANGPTL2 levels among patients after the surgery.
In $21(44.7 \%)$ patients (33.3\% CABG; $38.1 \% \mathrm{VR} ; 28.6 \%$ CABG+VR), plasma level of ANGPTL2 significantly decreased, whereas it significantly increased in $26(55.3 \%)$ patients (34.6\% CABG; 30.8\% VR; 34.6\% CABG+VR; Figure $1, B)$. In the INCREASED group, ANGPTL2 levels rose dramatically 24 hours after the surgery and remained at a high level thereafter. In contrast, in the DECREASED group, ANGPTL2 levels did not rise 24 hours postsurgery, and significantly decreased thereafter (Figure 1, B).

\section{Comparison of Plasma ANGPTL2 and hs-CRP Postoperative Levels}

Because increases in the circulating level of ANGPTL2 is a marker of inflammation, we though to assess its correlation with the level of hs-CRP. Globally, the postoperative temporal change of ANGPTL2 and hs-CRP levels was similar (Figure E3), this being confirmed by a generalized estimating equation model that compared the profile of both parameters in time $(P=.002)$. Postoperative hs-CRP levels were not influenced by the type of surgery (Figure E4). Importantly, the profile of plasma hs-CRP in the INCREASED and DECREASED groups did not differ $(P=.997$; Figure 1, $C)$.

\section{Discriminatory Parameters of INCREASED and DECREASED Groups of Patients}

In the DECREASED group, patients were 8 years younger ( $63 \pm 2$ versus $71 \pm 1$ years; $P=.002$; Table 2$)$ and had a lower systolic blood pressure (SBP; $124 \pm 5$ versus $136 \pm 3 \mathrm{~mm} \mathrm{Hg} ; P=.038$; Table 2). In addition, 24 hours after the surgery, patients in the DECREASED group received 20 times less norepinephrine bitartrate (Pfizer Canada, Kirkland, Quebec, Canada) (noradrenaline; $0.0018 \pm 0.002$ versus $0.035 \pm 0.018 \mathrm{mg} / \mathrm{h} ; P<.0001)$, suggestive of a milder inflammatory response and less vasoplegia after the stress induced by the surgery and the CPB. Previous myocardial infarction and other parameters such as sex, body mass index, or the presence of various cardiovascular risk factors had no significant influence on ANGPTL2, although patients in the DECREASED group tended $(P=.108$, not significant) to have less cumulative risk factors for CVD (Table 2). Paradoxically, patients in 
A

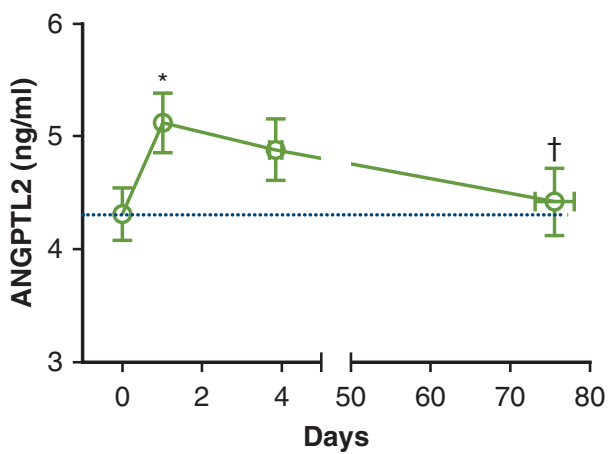

B

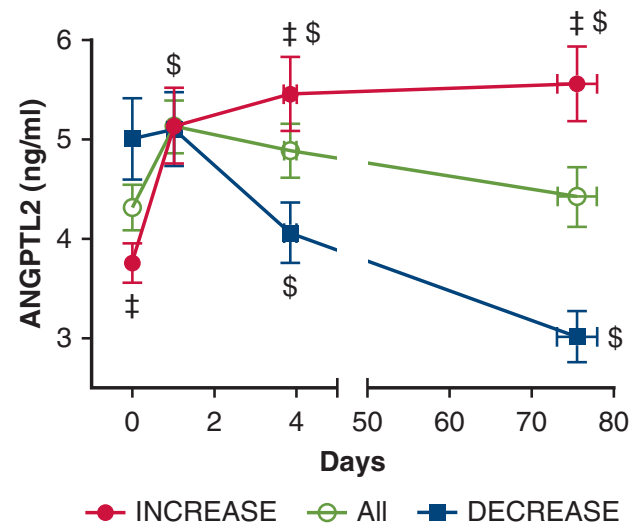

C

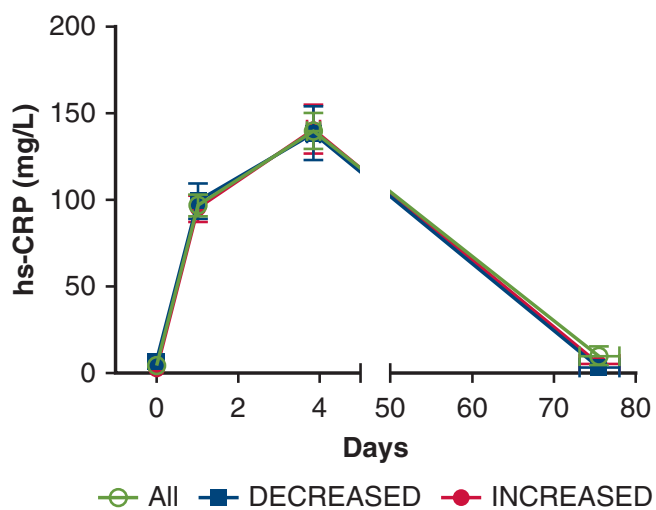

FIGURE 1. A, Mean plasma angiopoietin-like 2 (ANGPTL2) levels measured before and after 24 hours, at hospital discharge (3-5 days), and at the follow-up visit (30-90 days) after a cardiac surgery (coronary artery bypass grafting, valve replacement, or both). Data are mean \pm standard error of the mean (SEM) of 47 patients. One-way repeated measures analysis of variance (ANOVA; effect time $P=.002$ ): ${ }^{*} P=.001$ versus basal (time $0) ; \dagger P=.035$ versus 24 hours. B, Circulating levels of ANGPTL2 either decreased (DECREASED group, $\mathrm{n}=21$ ) or increased (INCREASED group, $n=26$ ) at the end of the follow-up (76 days after the surgery). The opposite patterns of change in ANGPTL2 levels among the patients are shown. For comparison, the mean profile of plasma ANGPTL2 measured in all patients is also shown. Data are mean \pm SEM of 47 patients. Two-way repeated measures ANOVA (interaction term between Group and Time $P<.0001) ; \ddagger P<.05$ versus DECREASED; $\$ P<.05$ the DECREASED group showed higher basal preoperative levels of ANGPTL2 $(P<.05$; Figure $1, B)$.

To more efficiently compare these 2 groups of patients, we measured the $\triangle$ ANGPTL2 (ie, postoperative ANGPTL2 levels measured at the end of the study minus preoperative ANGPTL2 levels), and performed correlations between this $\triangle$ ANGPTL2 value and various parameters characterizing each patient. As expected, we found that the older the patient, the higher the positive $\Delta$, or in other words, the greater the increase in ANGPTL2 levels $(r=0.338 ; P=.020$; $\mathrm{n}=47)$. A trend for a correlation was observed between $\triangle$ ANGPTL2 and SBP $(r=0.260 ; P=.096 ; \mathrm{n}=42)$ and between $\triangle$ ANGPTL2 and the use of angiotensin receptor antagonists $(r=0.261 ; P=.076 ; \mathrm{n}=47)$. We found a positive correlation between $\triangle$ ANGPTL2 and preoperative high-density lipoprotein (HDL) cholesterol levels $(r=0.414 ; P=.004 ; \mathrm{n}=47)$. In contrast, a negative correlation was found between basal heart rate and $\triangle$ ANGPTL2 $(r=-0.302 ; P=.039 ; \mathrm{n}=47)$.

Using a multiple backward linear regression model, we confirmed that HDL cholesterol levels $(P=.019)$ and the use of an angiotensin receptor antagonist $(P=.011)$ were independently and positively associated with $\triangle$ ANGPTL2, whereas heart rate $(P=.011)$ was independently and negatively associated with $\triangle$ ANGPTL2.

Although preoperative characteristics of the patients could influence $\triangle$ ANGPTL2, there was no significant differences in the operative parameters (Table E1) and in the clinical outcomes observed during the follow-up (from 3-5 to 30-90 days after surgery) between the patients in the INCREASED and the DECREASED group (Table 3). We only observed a possible trend for a lower rate of postoperative acute atrial fibrillation (AF) in patients in whom ANGPTL2 levels significantly decreased after the cardiac surgery $(14 \%$ versus $35 \% ; P=.112$, nonsignificant; Table 3). However, the incidence of new-onset AF after surgery did not differ between the 2 groups $(P=.290$; Table 3$)$.

\section{Gene Expression in MAT and IMA in Patients Who Underwent Cardiac Surgery}

Because the adipokine ANGPTL2 contributes to inflammation, fibrosis, and cellular senescence in AT and blood vessels, ${ }^{3}$ we quantified mRNA in MAT and IMA fragments for genes known to be regulated by ANGPTL2 and/or to promote ANGPTL2 gene expression. ${ }^{18}$ Surprisingly, plasma ANGPTL2 levels at baseline did not correlate with any of

versus basal $(\mathrm{t}=0)$, in each group of patients. C, Mean plasma highsensitivity C-reactive protein (hs-CRP) levels after cardiac surgery in all patients and in whom ANGPTL2 levels either decreased or increased. Data are mean \pm SEM of 47 patients. Two-way repeated measures ANOVA was performed (effect of Group $P=.997$; Time $P<.0001$; Group $\times$ Time $P=.375)$. 
TABLE 2. Comparison of preoperative parameters in the 2 groups of patients with positive (INCREASED group) or negative (DECREASED group) $\triangle$ ANGPTL2

\begin{tabular}{|c|c|c|c|}
\hline Parameter & $\begin{array}{c}\text { Negative } \Delta \\
\text { (ANGPTL2 } \\
\text { decreased; } \\
\mathbf{n}=\mathbf{2 1} \text { ) }\end{array}$ & $\begin{array}{c}\text { Positive } \Delta \\
\text { (ANGPTL2 } \\
\text { increased; } \\
\mathbf{n}=\mathbf{2 6} \text { ) }\end{array}$ & $P$ value \\
\hline Age, y & $63 \pm 2$ & $71 \pm 1$ & .002 \\
\hline BMI & $28.2 \pm 4.4$ & $29.7 \pm 5.1$ & .405 \\
\hline Obesity & $8(38)$ & $14(54)$ & .282 \\
\hline Women & $4(19)$ & $6(23)$ & .737 \\
\hline Type 2 diabetes & $7(33)$ & $11(42)$ & .529 \\
\hline Dyslipidemia & $16(76)$ & $22(84)$ & .466 \\
\hline Hypertension & $14(67)$ & $21(81)$ & .270 \\
\hline $\mathrm{SBP}, \mathrm{mm} \mathrm{Hg}$ & $124 \pm 5(19)$ & $136 \pm 3(23)$ & .038 \\
\hline DBP, mm Hg & $71 \pm 4$ (19) & $74 \pm 2(23)$ & .866 \\
\hline HR, beats per minute & $79 \pm 3$ & $73 \pm 2$ & .078 \\
\hline Active smoker & $3(14)$ & $4(15)$ & .916 \\
\hline Ex-smokers & $6(29)$ & 7 (27) & .900 \\
\hline COPD & $1(5)$ & $4(15)$ & .240 \\
\hline Family history & $5(24)$ & $9(35)$ & .421 \\
\hline Chronic renal dysfunction & $1(5)$ & $3(12)$ & .408 \\
\hline Previous MI & $5(24)$ & $5(19)$ & .703 \\
\hline Preoperative AF & $5(24)$ & $7(27)$ & .800 \\
\hline $\begin{array}{l}\text { At least } 6 \text { risk factors } \\
\text { for CVD }\end{array}$ & $11(52)$ & $17(65)$ & .108 \\
\hline
\end{tabular}

Data are mean \pm standard deviation or $\mathrm{n}(\%)$ except where otherwise noted. The $\chi^{2}$ test was used except for the comparison of age, BMI, and blood pressure between groups. $P<.05$ are indicated in bold. ANGPTL2, Angiopoietin-like 2; BMI, body mass index; $S B P$, systolic blood pressure; $D B P$, diastolic blood pressure; $H R$, heart rate; $C O P D$, chronic obstructive pulmonary disease; $M I$, myocardial infarction; $A F$, atrial fibrillation; $C V D$, cardiovascular disease.

the genes tested in MAT and IMA (Table E3). Similarly, no obvious association was found between basal hs-CRP levels and the expression of inflammatory or senescence markers in MAT and IMA (only $T N F-\alpha$ and hs-CRP in MAT were positively correlated; $P=.024$; Table E4).

In contrast, in MAT, $\triangle \mathrm{ANGPTL} 2$ was positively correlated to the mRNA expression of $T N F-\alpha(P=.046)$ and $I L-8(P=.0004$; Figure $2, A$ and Table 4$)$, whereas a trend was observed for $I L-6(P=.064$; Table 4). TNF- $\alpha$ $(P=.029)$ and $I L-8(P=.006)$ expression were higher in the INCREASED group of patients whereas ANGPTL2, adiponectin and transforming growth factor $\beta 1$ expressions were similar in MAT in patients in whom ANGPTL2 levels either decreased or increased (Figure E5, $A$ ). In IMA, the $\triangle$ ANGPTL2 was also positively correlated with the amount of $T N F-\alpha$ mRNA $(P=.031$; Figure $2, B), I L-8(P=.015$; Table 4), as well as $p 21(P=.009$; Figure $2, B) . I L-8$ $(P=.099)$ and $p 21(P=.079) \mathrm{mRNA}$ also tended to be more abundant in patients in whom ANGPTL2 levels
TABLE 3. Clinical outcomes of the patients according to their $\triangle$ ANGPTL2

\begin{tabular}{lccc}
\hline & $\begin{array}{c}\text { Negative } \boldsymbol{\Delta} \\
\text { (ANGPTL2 } \\
\text { decreased; } \\
\mathbf{n}=\mathbf{2 1})\end{array}$ & $\begin{array}{c}\text { Positive } \boldsymbol{\Delta} \\
\text { (ANGPTL2 } \\
\text { increased; } \\
\mathbf{n}=\mathbf{2 6})\end{array}$ & $\boldsymbol{P}$ value \\
\hline At least 1 event observed & $7(33)$ & $13(50)$ & .251 \\
$\begin{array}{l}\text { Implantation of a } \\
\text { pacemaker }\end{array}$ & $2(10)$ & $5(19)$ & .353 \\
\hline AF & $3(14)$ & $9(35)$ & .112 \\
New-onset of AF & $3(14)$ & $7(27)$ & .290 \\
\hline Acute renal dysfunction* & $2(10)$ & $4(15)$ & .549 \\
AV block & $2(10)$ & $2(8)$ & .823 \\
\hline
\end{tabular}

$A N G P T L 2$, Angiopoietin-like $2 ; A F$, atrial fibrillation; $A V$, atrioventricular. *Characterized by an increase of $50 \%$ of preoperative creatinine value.

increased after surgery (Figure E5, B). These data suggest a more preoperative inflammatory and senescent environment in the adipose and vascular tissues in patients whose ANGPTL2 level will rise postoperatively, independently of ANGPTL2 levels at baseline.

\section{DISCUSSION}

In this study, we showed a dichotomy in plasma ANGPTL2 level variations after a cardiac surgery (Figure 3). We identified 2 different groups of patients according to their plasma ANGPTL2 levels during followup: in half of the patient population, ANGPTL2 levels declined (DECREASED group), whereas in the other half, ANGPTL2 levels rose (INCREASED group). Preoperative characteristics such as age, SBP, HDL levels, and heart rate, tissue inflammation, and senescence load of the patient's tissues were correlated with ANGPTL2 levels. In young patients with a well controlled SBP, with low expression levels of inflammation $(T N F \alpha$ and $I L-8)$ and senescence ( $p 21)$ marker genes in adipose and arterial tissues, ANGPTL2 levels decreased significantly after cardiac surgery. Our data suggest therefore that the preoperative tissue inflammatory and senescence load of the patient could determine the plasma level of ANGPTL2 after cardiac surgery (Figure 3).

In a 10-year follow-up study of a Japanese population originally without CVD, it has been shown that the risk of major adverse cardiovascular events increased with higher circulating levels of ANGPTL2, ${ }^{4}$ making ANGPTL2 a novel risk factor for the development of CVD. There are several mechanisms by which ANGPTL2 could cause CVD: ANGPTL2 induces endothelial dysfunction ${ }^{6,19}$ and accelerates atherogenesis. ${ }^{5}$ ANGPTL2 is also an adipokine and a mediator linking CVD to risk factors such as obesity/ insulin resistance and tissue inflammation. ${ }^{2}$ Hence, ANGPTL2 could contribute to the initiation and the 

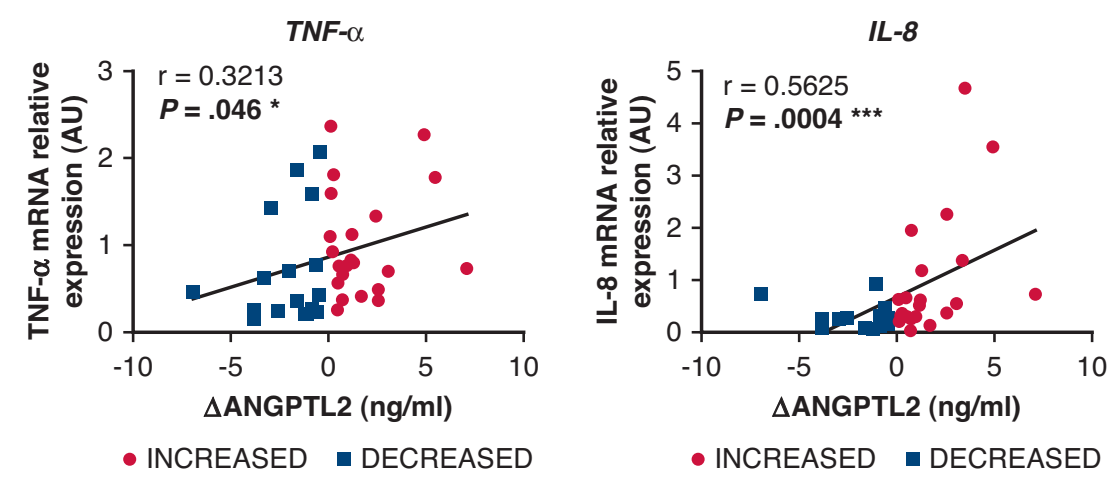

A
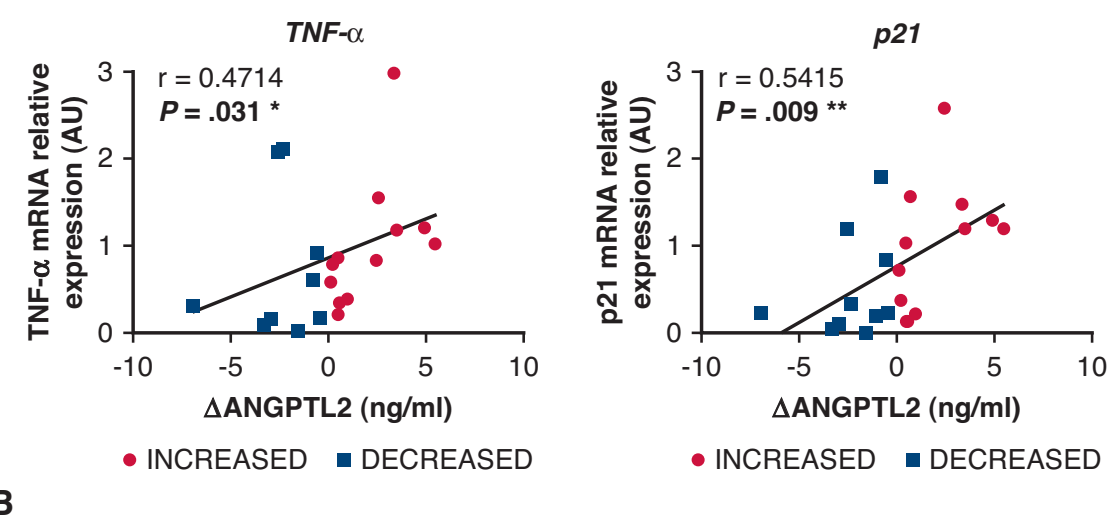

FIGURE 2. Linear correlations between $\Delta$ angiopoietin-like 2 (ANGPTL2) levels ( $\triangle$ ANGPTL2: plasma ANGPTL2 levels measured at the end of the follow-up minus plasma ANGPTL2 measured at baseline) and inflammatory (tumor necrosis factor $[T N F]-\alpha$ and interleukin $[I L]-8$ mRNA expression) and senescent (cyclin-dependent kinase inhibitor 1 [p21] mRNA expression) markers in (A) mediastinal adipose tissue (MAT) and in (B) internal mammary artery (IMA) tissues. Data are individual values of 44 patients in MAT and of 23 patients in IMA, in whom $\triangle$ ANGPTL2 either increased (INCREASED) or decreased (DECREASED). $* P<.05 ; * * P<.01 ; * * * P<.001$. $A U$, Arbitrary units.

progression of atherosclerosis. The specific role of ANGPTL2 in cardiac function is, however, less known. High serum levels of ANGPTL2 have been shown to be an independent predictor of heart failure ${ }^{12}$; however, levels of ANGPTL2 were not different between patients with ischemic and nonischemic cardiomyopathy, or between patients with and without left ventricular ejection fraction. ${ }^{12}$ In a recent study, Tian and colleagues showed that in mice, an increase in ANGPTL2 levels did not promote cardiac dysfunction, but rather reflected it. ${ }^{14}$ However, it has been proposed that an increase in cardiac ANGPTL2 expression and secretion could accelerate heart failure and that therapeutic ANGPTL2 inactivation could be beneficial. ${ }^{13}$ In the present study, cardiac function was normal in all patients and thus, ANGPTL2 rather reflected the global burden of age and risk factors for CVD.

In a subgroup of patients, cardiac surgery lowered ANGPTL2 levels. This is the first demonstration that a cardiac surgery such as CABG, VR, or both, affects circulating levels of ANGPTL2 and discriminates between 2 populations of patients. It has been previously shown that the quantity of ANGPTL2 mRNA in epicardial AT was similar in coronary heart disease (CHD) patients who underwent CABG and in non-CHD patients who underwent VR. ${ }^{18}$ Accordingly, we found that tissue expression of ANGPTL2 was similar between the 2 populations of patients, and that the type of cardiac surgery (CABG, VR, or both) had no significant effect on the postoperative changes in plasma ANGPTL2 levels. In contrast, differences between pre-/post surgery plasma ANGPTL2 were related to several preoperative parameters. The age of the patients, their SBP, and also their heart rate and HDL cholesterol levels were determinant: the younger the patient, the lower his/her blood pressure and HDL levels, the higher the heart rate, the greater the decrease in plasma ANGPTL2. The fact that young age is associated with a pattern of lower ANGPTL2 is not surprising: ANGPTL2 levels are known to rise progressively with age in mice ${ }^{5}$ and in humans, ${ }^{6}$ and with the severity of atherosclerosis. ${ }^{5,20}$ However, we have no explanation why high heart rate and 
TABLE 4. Significant correlations between $\triangle$ ANGPTL2 (in the plasma) and inflammatory and senescent gene markers (mRNA) in MAT and IMA segments

\begin{tabular}{lccc}
\hline Tissue & $\begin{array}{c}\text { Gene expression } \\
\text { versus } \text { AANGPTL2 }\end{array}$ & $\boldsymbol{r}$ (Spearman) & $\boldsymbol{P}$ value \\
\hline MAT & $A N G P T L 2$ & -0.09105 & .557 \\
& $T N F-\alpha$ & 0.3213 & $\mathbf{. 0 4 6}$ \\
& $I L-8$ & 0.5625 & $\mathbf{. 0 0 0 4}$ \\
& $I L-6$ & 0.3122 & $\mathbf{. 0 6 4}$ \\
\hline IMA & $p 21$ & 0.08624 & .602 \\
& $A N G P T L 2$ & 0.1419 & .324 \\
& $T N F-\alpha$ & 0.4714 & $\mathbf{. 0 3 1}$ \\
& $I L-8$ & 0.5020 & $\mathbf{. 0 1 5}$ \\
\hline & $I L-6$ & 0.3247 & .151 \\
\hline
\end{tabular}

Data are mean \pm standard error of the mean of 44 patients in MAT and 23 patients in IMA. $P<.05$ are indicated in bold. ANGPTL2, Angiopoietin-like 2; MAT, mediastinal adipose tissue; TNF, tumor necrosis factor; IL, interleukin; p21, cyclin-dependent kinase inhibitor 1; IMA, internal mammary artery.

low HDL levels were associated with a decrease in ANGPTL2. Circulating levels of ANGPTL2 reflect the severity of atherosclerosis, but not dyslipidemia, ${ }^{6}$ and basal ANGPTL2 levels have been reported to be negatively, not positively, correlated with HDL levels in heart failure ${ }^{12}$ and diabetic patients. ${ }^{11}$

Paradoxically, basal levels of ANGPTL2 were higher in the group of patients in whom ANGPTL2 levels decreased after the surgery. High ANGPTL2 levels are indeed considered as a risk factor for CVD. ${ }^{4}$ Patients in the DECREASED group were 8 years younger, suggesting that they had a premature coronary disease. Neither basal ANGPTL2 nor hs-CRP levels were correlated with the expression of inflammatory and senescence gene markers in MAT and IMA. In contrast, changes in plasma ANGPTL2 levels at the end of the study were clearly associated with tissue inflammation and senescence, suggesting that the change in ANGPTL2 levels in response to an inflammatory stress is more informative than its baseline levels. The effect of the cardiac surgery on plasma ANGPTL2 levels seems therefore complex and difficult to explain on the basis of classical clinical parameters such as age, blood pressure, or HDL levels, or on the basis of steady state ANGPTL2 levels per se.

We originally isolated ANGPTL2 from senescent endothelial cells of IMA segments discarded during CABG surgeries $^{21}$ and we hypothesized that the level of tissue inflammation and the "biological age" of the patients contributes to modulate ANGPTL2 levels in response to the inflammatory stress of the surgery. Our study validates this hypothesis through 2 important associations: (1) a significant positive correlation between high plasma ANGPTL2 levels postsurgery and high expression of the inflammatory gene markers $T N F-\alpha$ and $I L-8$ in the adipose and vascular tissues at baseline; and (2) a significant correlation between high plasma ANGPTL2 levels postsurgery and the elevated vascular expression of the senescence gene marker $p 21$. Hence, our data suggest that the change in plasma ANGPTL2 levels postsurgery reflects the preoperative tissue inflammatory and senescence load of the patient. In other words, the "biological age" of the tissues determines the adaptive response to a stressor. Previous studies quantified ANGPTL2 mRNA in epicardial AT: in CHD patients, a positive correlation was found between ANGPTL2 and $T N F-\alpha$ expression. ${ }^{18}$ Abe and colleagues recently showed that the expression of inflammatory cytokines is positively correlated with ANGPTL2 gene expression in epicardial AT in patients with AF, suggesting that ANGPTL2 could be involved in maintaining an inflammatory environment in cardiac AT and contribute to $\mathrm{AF}^{22}$ In support of this contention, increased ANGPTL2 mRNA within the atrial appendage correlates with susceptibility to AF, but precedes ionic remodeling, and hence might be a biomarker for subsequent transcriptional remodeling. ${ }^{23}$ Interestingly, we observed a potential tendency to experience less AF shortly after the cardiac surgery in the DECREASED group characterized by a lower basal expression of inflammatory markers in AT.

High plasma ANGPTL2 levels postsurgery were significantly associated with the elevated expression of the senescence marker $p 21$ in IMA segments. ANGPTL2, among other cytokines and growth factors, is secreted by senescent cells, and inflammation promotes ANGPTL2 expression and senescence $^{3}$; thus, senescence begets senescence. Recent preclinical studies suggest that senescent cells cause endothelial dysfunction $^{24}$ and atherosclerosis. ${ }^{25}$ The association between ANGPTL2 levels postsurgery and p21 in elderly patients with high SBP supports the concept that senescent cells accumulate with age, ${ }^{26}$ that this accumulation is magnified by risk factors for $\mathrm{CVD}^{27}$ and leads to atherosclerosis. ${ }^{25}$

Finally, we found a significant association between plasma ANGPTL2 and hs-CRP levels, as expected from the literature. ANGPTL2 levels are indeed closely associated with hs-CRP levels in obesity, ${ }^{2}$ diabetes, ${ }^{11}$ acute coronary syndrome, ${ }^{10}$ heart failure, ${ }^{12}$ and cancer, ${ }^{28}$ but also in the general population. ${ }^{4,29}$ However, unlike ANGPTL2 levels, a postoperative dichotomy was not observed with hs-CRP, strengthening the concept that assessing plasma ANGPTL2 could have the added benefit of stratifying patients with CVD. This potential advantage of ANGPTL2 over hs-CRP has been previously suggested in patients with acute coronary syndrome in whom serum ANGPTL2 levels correlated with stable CAD, whereas hs-CRP levels did not. ${ }^{10}$ Altogether, these data suggest that ANGPTL2 might be more than a simple marker of inflammation. ${ }^{3}$ The measurement of $\triangle$ ANGPTL2 does not permit prediction of the success of the cardiac surgery; rather, and unlike hs-CRP, it allows determination of the inflammatory and 


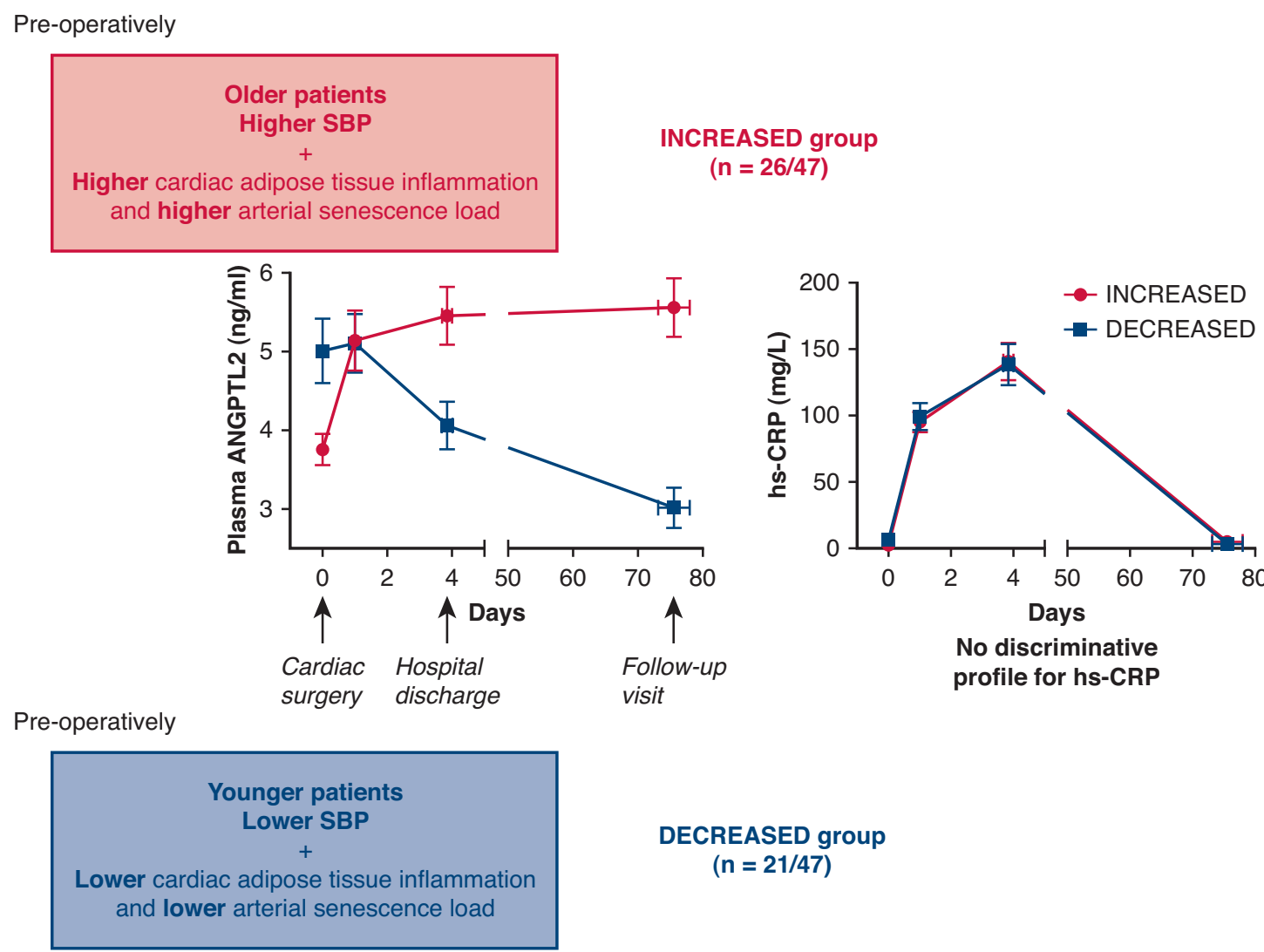

FIGURE 3. Plasma angiopoietin-like 2 (ANGPTL2) levels were measured before and after 24 hours, at hospital discharge, and at the follow-up visit after a cardiac surgery (coronary artery bypass grafting, valve replacement, or both). Circulating levels of ANGPTL2 either decreased (DECREASED group, $\mathrm{n}=21$ ) or increased (INCREASED group, $\mathrm{n}=26$ ) at the end of the follow-up. In the INCREASED group, the patients were older and had a higher systolic blood pressure and their cardiac adipose tissue and arterial tissue exhibited higher expression level of markers of inflammation and senescence, respectively. In the DECREASED group, reduced ANGPTL2 levels after cardiac surgery reflected lower cardiac adipose tissue inflammation and lower arterial senescence. In contrast to ANGPTL2, changes in high-sensitivity C-reactive protein (hs-CRP) circulating levels did not reflect the preoperative inflammation and senescence load of the patients. SBP, Systolic blood pressure.

senescence status of the patient. The effect of $\triangle$ ANGPTL2 on postoperative events remains to be shown in a larger population and with a longer clinical follow-up. Higher postoperative ANGPTL2 levels observed in the INCREASED group could be a predictor of CVD or cardiovascular events during the follow-up, such as AF or coronary disease.

\section{Study Limitation}

This study has several limitations. First, the number of patients included in this study $(\mathrm{n}=47)$ is relatively small, limiting the statistical power of the correlations between mRNA expression of inflammatory markers and ANGPTL2 levels and the estimation of a significant effect of the dichotomy in ANGPTL2 responses after cardiac surgery on the number and severity of events observed postoperatively. In the group of patients in whom ANGPTL2 levels decreased, we found a tendency for less AF, but it did not reach statistical significance. The expected low frequency of clinical events observed postoperatively, together with the relatively low number of patients, might have prevented identification of whether the changes in ANGPTL2 levels reflected a beneficial or a deleterious postoperative clinical outcome. Alternatively, a longer follow-up would be needed. Second, the last plasma measurement of ANGPTL2 was performed within 30 to 90 postoperative days, representing a large time span with a standard deviation of 17 days between surgery and the last measurement of ANGPTL2. CPB-related inflammation is expected to significantly vary during this time span, and it could potentially affect ANGPTL2 levels. However, no correlation was found between $\mathrm{CPB}$ duration and ANGPTL2 levels or $\triangle$ ANGPTL2 (data not shown), suggesting that the dichotomy observed in ANGPTL2 levels is independent from CPB duration. Third, only plasma hs-CRP levels were simultaneously measured with ANGPTL2 levels, limiting the mechanistic interpretation of our results. Measurements of other circulating markers such as IL- 8 and TNF- $\alpha$ could refine our understanding of the dichotomy of the change of ANGPTL2 after cardiac surgery. 


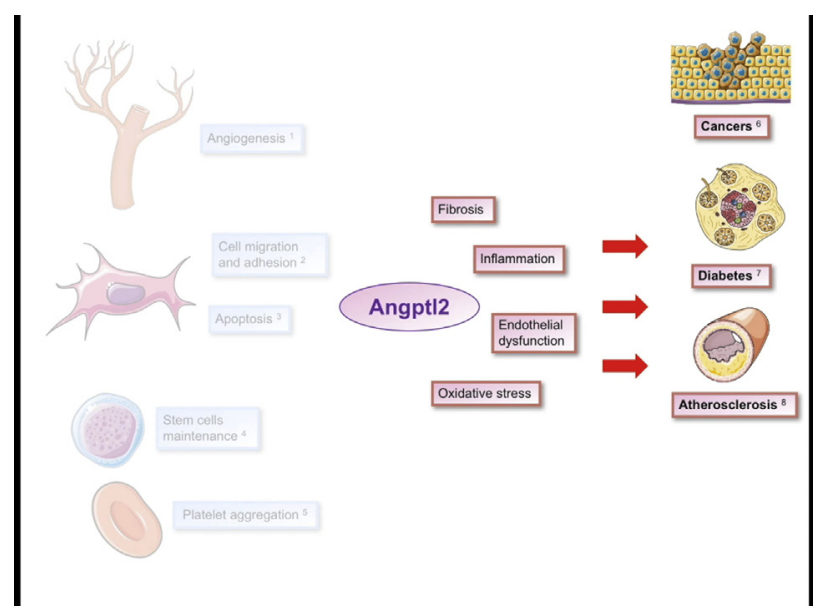

VIDEO 1. Summary of the current study; context, methods, main results, and clinical perspectives. Video available at: https://www.jtcvs.org/article/ S0022-5223(18)33486-X/fulltext.

\section{CONCLUSIONS}

We report for the first time that the circulating levels of ANGPTL2 were either reduced or increased after cardiac surgery, depending on preoperative tissue inflammatory and senescence status of the patients, in addition to the age and some preoperative characteristics (Video 1). This dichotomy was not observed with hs-CRP, suggesting that ANGPTL2 could be more than an inflammatory marker. ANGPTL2 is one of the multiple molecules secreted by senescent cells, referred to as the senescence-associatedsecretory-phenotype, and high circulating ANGPTL2 levels observed in patients with chronic inflammatory diseases could reflect the senescent cellular load of an individual. ${ }^{3}$ The molecular mechanisms underlying senescenceassociated-secretory-phenotype-derived ANGPTL2 secretion and ANGPTL2-induced senescence are unknown. These observations warrant further evaluation in a larger population of patients who undergo cardiac surgery to validate the potential of such dichotomy in predicting the severity/incidence of postsurgery cardiovascular events. Assessing pre- and postoperative plasma ANGPTL2 levels might help physicians to better individualize medical treatment according to the risk.

\section{Conflict of Interest Statement}

Authors have nothing to disclose with regard to commercial support.

\section{References}

1. Hansson GK, Libby P, Tabas I. Inflammation and plaque vulnerability. J Intern Med. 2015;278:483-93.

2. Tabata M, Kadomatsu T, Fukuhara S, Miyata K, Ito Y, Endo M, et al. Angiopoietin-like protein 2 promotes chronic adipose tissue inflammation and obesity-related systemic insulin resistance. Cell Metab. 2009;10:178-88.

3. Thorin-Trescases N, Thorin E. High circulating levels of ANGPTL2: beyond a clinical marker of systemic inflammation. Oxid Med Cell Longev. 2017;2017: 1096385.
4. Hata J, Mukai N, Nagata M, Ohara T, Yoshida D, Kishimoto H, et al. Serum angiopoietin-like protein 2 is a novel risk factor for cardiovascular disease in the community: the Hisayama study. Arterioscler Thromb Vasc Biol. 2016;36: 1686-91.

5. Farhat N, Thorin-Trescases N, Mamarbachi M, Villeneuve L, Yu C, Martel C, et al. Angiopoietin-like 2 promotes atherogenesis in mice. J Am Heart Assoc. 2013;2:e000201.

6. Horio E, Kadomatsu T, Miyata K, Arai Y, Hosokawa K, Doi Y, et al. Role of endothelial cell-derived angptl2 in vascular inflammation leading to endothelial dysfunction and atherosclerosis progression. Arterioscler Thromb Vasc Biol. 2014;34:790-800.

7. Larouche JF, Yu C, Luo X, Farhat N, Guiraud T, Lalonge J, et al. Acute high-intensity intermittent aerobic exercise reduces plasma angiopoietin-like 2 in patients with coronary artery disease. Can J Cardiol. 2015;31:1232-9.

8. Nguyen A, Mamarbachi M, Turcot V, Lessard S, Yu C, Luo X, et al. Lower methylation of the ANGPTL2 gene in leukocytes from post-acute coronary syndrome patients. PLoS One. 2016;11:e0153920.

9. Thorin-Trescases N, Hayami D, Yu C, Luo X, Nguyen A, Larouche JF, et al. Exercise lowers plasma angiopoietin-like 2 in men with post-acute coronary syndrome. PLoS One. 2016;11:e0164598.

10. Wang Z, Zheng H, Chen H, Lin X, Chen J, Wang L, et al. Elevated serum angiopoietin-like protein 2 in patients with acute coronary syndrome. Arch Med Res. 2015;46:257-64.

11. Jung CH, Lee WJ, Lee MJ, Kang YM, Jang JE, Leem J, et al. Association of serum angiopoietin-like protein 2 with carotid intima-media thickness in subjects with type 2 diabetes. Cardiovasc Diabetol. 2015;14:35.

12. Huang CL, Wu YW, Wu CC, Hwang JJ, Yang WS. Serum angiopoietin-like protein 2 concentrations are independently associated with heart failure. PLoS One. 2015;10:e0138678.

13. Tian Z, Miyata K, Kadomatsu T, Horiguchi H, Fukushima H, Tohyama S, et al ANGPTL2 activity in cardiac pathologies accelerates heart failure by perturbing cardiac function and energy metabolism. Nat Commun. 2016;7:13016.

14. Tian Z, Miyata K, Morinaga J, Horiguchi H, Kadomatsu T, Endo M, et al Circulating ANGPTL2 levels increase in humans and mice exhibiting cardiac dysfunction. Circ J. 2018;82:437-47.

15. Oike Y, Tian Z, Miyata K, Morinaga J, Endo M, Kadomatsu T. ANGPTL2- a new causal player in accelerating heart disease development in the aging. Circ $J$ 2017;81:1379-85.

16. Doi Y, Ninomiya T, Hirakawa Y, Takahashi O, Mukai N, Hata J, et al Angiopoietin-like protein 2 and risk of type 2 diabetes in a general Japanese population: the Hisayama study. Diabetes Care. 2013;36:98-100.

17. Gellen B, Thorin-Trescases N, Sosner P, Gand E, Saulnier PJ, Ragot S, et al ANGPTL2 is associated with an increased risk of cardiovascular events and death in diabetic patients. Diabetologia. 2016;59:2321-30.

18. Tian Z, Miyata K, Tazume H, Sakaguchi H, Kadomatsu T, Horio E, et al. Perivascular adipose tissue-secreted angiopoietin-like protein 2 (Angpt12) accelerates neointimal hyperplasia after endovascular injury. J Mol Cell Cardiol. 2013;57:1-12.

19. Yu C, Luo X, Farhat N, Daneault C, Duquette N, Martel C, et al. Lack of angiopoietin-like-2 expression limits the metabolic stress induced by a high-fat diet and maintains endothelial function in mice. J Am Heart Assoc. 2014;3: e001024.

20. Oike Y, Tabata M. Angiopoietin-like proteins-potential therapeutic targets for metabolic syndrome and cardiovascular disease. Circ J. 2009;73:2192-7.

21. Farhat N, Thorin-Trescases N, Voghel G, Villeneuve L, Mamarbachi M, Perrault LP, et al. Stress-induced senescence predominates in endothelial cells isolated from atherosclerotic chronic smokers. Can J Physiol Pharmacol. 2008;86:761-9.

22. Abe I, Teshima Y, Kondo H, Kaku H, Kira S, Ikebe Y, et al. Association of fibrotic remodeling and cytokines/chemokines content in epicardial adipose tissue with atrial myocardial fibrosis in patients with atrial fibrillation. Heart Rhythm. 2018; 15:1717-27.

23. Deshmukh A, Barnard J, Sun H, Newton D, Castel L, Pettersson G, et al. Left atrial transcriptional changes associated with atrial fibrillation susceptibility and persistence. Circ Arrhythm Electrophysiol. 2015;8:32-41.

24. Roos CM, Zhang B, Palmer AK, Ogrodnik MB, Pirtskhalava T, Thalji NM, et al Chronic senolytic treatment alleviates established vasomotor dysfunction in aged or atherosclerotic mice. Aging Cell. 2016;15:973-7.

25. Childs BG, Baker DJ, Wijshake T, Conover CA, Campisi J, van Deursen JM Senescent intimal foam cells are deleterious at all stages of atherosclerosis. Science. 2016;354:472-7. 
26. van Deursen JM. The role of senescent cells in ageing. Nature. 2014;509:439-46.

27. Minamino T, Miyauchi H, Yoshida T, Ishida Y, Yoshida H, Komuro I. Endothelia cell senescence in human atherosclerosis: role of telomere in endothelial dysfunction. Circulation. 2002;105:1541-4.

28. Yoshinaga $T$, Shigemitsu $T$, Nishimata H, Kitazono M, Hori E, Tomiyoshi A, et al. Angiopoietin-like protein 2 as a potential biomarker for colorectal cancer. Mol Clin Oncol. 2015;3:1080-4.
29. Usui T, Ninomiya $T$, Nagata M, Takahashi O, Doi $Y$, Hata J, et al Angiopoietin-like protein 2 is associated with chronic kidney disease in a general Japanese population: the Hisayama Study. Circ J. 2013;77:2311-7.

Key Words: ANGPTL2, mediastinal adipose tissue, internal mammary artery, $p 21, I L-8, T N F-\alpha$, cardiac surgery 


\section{APPENDIX E1. BLOOD AND TISSUE COLLECTION AND BIOCHEMICAL ANALYSIS}

Blood samples collected after a 12-hour overnight fast were rapidly placed on ice, centrifuged within minutes, and plasma collected, frozen in liquid nitrogen, and stored in aliquots at $-80^{\circ} \mathrm{C}$ until further analysis. Plasma lipid lipoprotein profile (total cholesterol, low-density lipoprotein and HDL cholesterol, triglycerides), inflammatory profile (hs-CRP and white blood cell count), renal status (creatinine levels and estimated glomerular filtration rate) and plasma glycated hemoglobin A1c were measured at the biochemical laboratory of the Montreal Heart Institute.

\section{PLASMA ANGIOPOIETIN-LIKE 2 PROTEIN LEVELS}

Plasma ANGPTL2 levels were measured using enzymatic immunoassay as per the manufacturer's instructions (Cloud-Clone Corporation, catalogue number SEB919HU, Houston, Tex) and as previously described. ${ }^{\mathrm{E} 1, \mathrm{E} 2}$ Plasma ANGPTL2 values were expressed as $\mathrm{ng} / \mathrm{mL}$ and the relevant measuring range is from 0.312 to $40 \mathrm{ng} / \mathrm{mL}$.

\section{TOTAL RNA EXTRACTION IN MAT AND IMA}

Frozen MAT and IMA fragments were pulverized in liquid nitrogen and dry ice with a cell crusher kit (Cellcrusher Ltd, Portland, Ore). Samples of organ powder were then processed for RNA extraction according to the manufacturer's instructions (RNeasy Lipid tissue mini kit and RNeasy mini kit, Qiagen) (Qiagen Canada, Montreal,
Quebec, Canada). Contamination with DNA was prevented by a digestion with a DNase I mix (Qiagen) according to the manufacturer's guidelines. Total RNA was quantified using a NanoDrop ND-100 spectrophotometer (Thermo Fisher Scientific, Waltham, Mass).

\section{REAL-TIME REVERSE TRANSCRIPTION- POLYMERASE CHAIN REACTION}

Total RNA was reverse-transcribed into first-strand complementary DNA with Moloney Murine Leukemia Virus reverse transcriptase (Invitrogen) (Thermo Fisher Scientific, Waltham, Mass) using random hexamer primers. The primers of target genes were designed using Clone Manager software version 9.51 (Sci-Ed Software, Denver, Colo) (Table E2). Quantitative polymerase chain reaction was performed using the SYBR Green PCR Master Mix (Applied Biosystems, Foster City, Calif). All samples were run in duplicate and the fold changes in gene expression were calculated using a $\Delta \Delta \mathrm{C}_{\mathrm{T}}$ (cycle threshold) method using GAPDH (glyceraldehyde-3-Phosphate Dehydrogenase) as the housekeeping gene. Data are expressed as arbitrary units.

\section{References}

E1. Gellen B, Thorin-Trescases N, Sosner P, et al. ANGPTL2 is associated with an increased risk of cardiovascular events and death in diabetic patients. Diabetologia. 2016;59:2321-30.

E2. Thorin-Trescases N, Hayami D, Yu C, et al. Exercise lowers plasma angiopoietin-like 2 in men with post-acute coronary syndrome. PLoS One 2016;11:e0164598. 


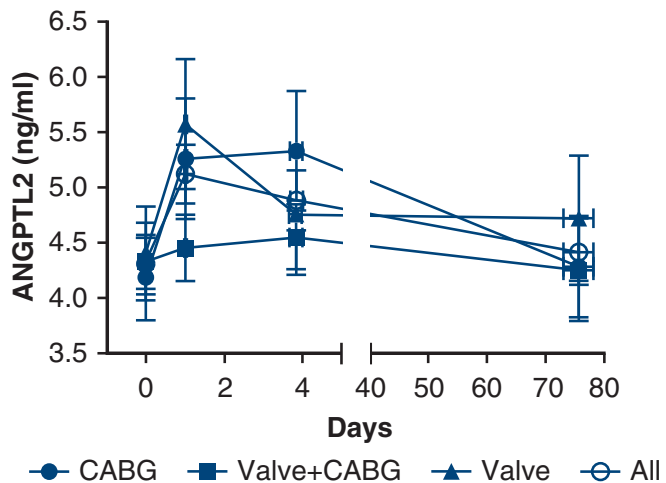

FIGURE E1. Temporal change in plasma angiopoietin-like 2 (ANGPTL2) levels after a cardiac surgery such as valve replacement (Valve, $n=16$ ), coronary artery bypass graft (CABG, $n=16$ ), both (Valve $+\mathrm{CABG}, \mathrm{n}=15$ ), or all types of surgery altogether (All, $n=47)$. Data are mean \pm standard error of the mean of a total of 47 patients.

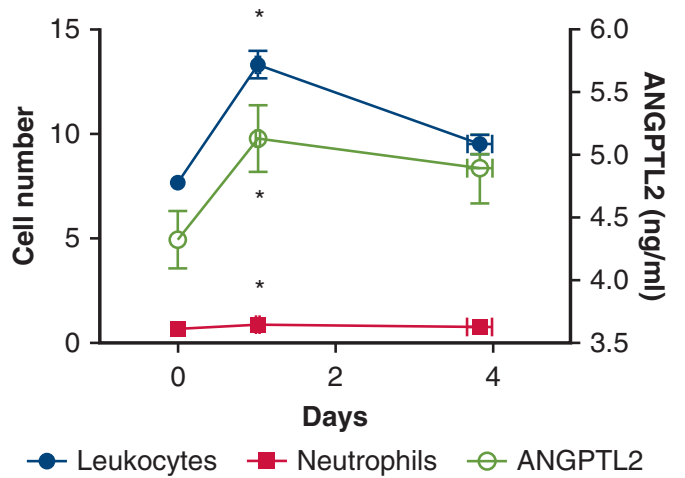

FIGURE E2. Acute changes of plasma angiopoietin-like 2 (ANGPTL2) levels and leukocytes and neutrophils number $\left(\times 10^{9}\right.$ cells $) 24$ hours and 3 to 5 days (at hospital discharge) after a cardiac surgery. Data are mean \pm standard error of the mean of 47 patients. One-way repeated measures analysis of variance; $* P<.05$ versus basal (time 0 ).

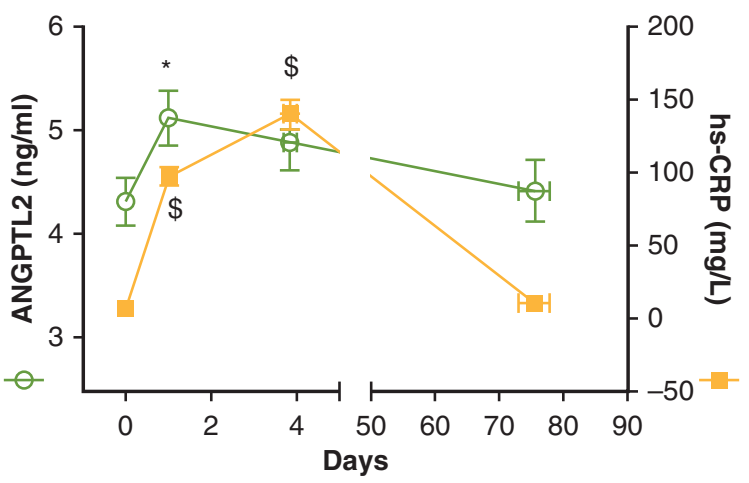

FIGURE E3. Comparison of plasma angiopoietin-like 2 (ANGPTL2) and plasma high-sensitivity C-reactive protein (hs-CRP) levels after cardiac surgery (valve replacement, coronary artery bypass, or both) in patients with cardiovascular diseases. Data are mean \pm standard error of the mean of 47 patients. One-way repeated measures analysis of variance (effect time, $P<.05$ ) was performed for each blood marker: $* P<.05$ versus basal (time 0 ) for ANGPTL2; $\$ P<.05$ versus basal (time 0 ) for hs-CRP.

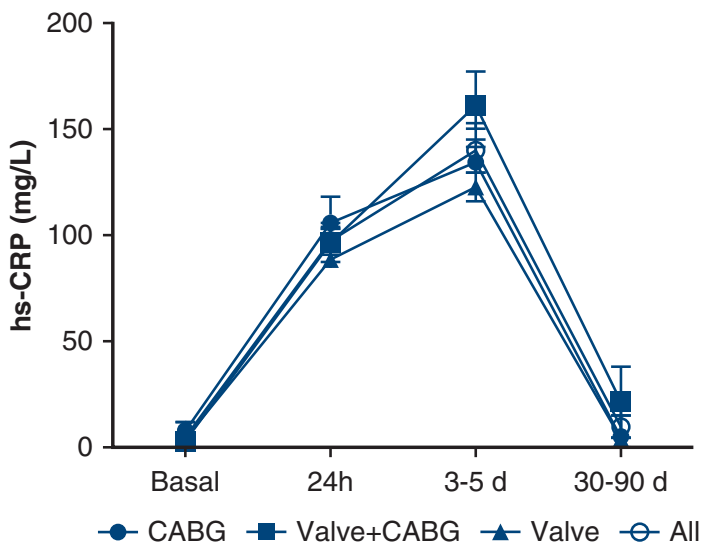

FIGURE E4. Temporal change in plasma high-sensitivity $C$-reactive protein (hs-CRP) levels before (Basal) and after (24 hours, 3-5 days at hospital discharge, 30-90 days for a follow-up visit) after cardiac surgery such as valve replacement (Valve, $\mathrm{n}=15$ ), coronary artery bypass graft (CABG, $\mathrm{n}=16)$, both $(\mathrm{CABG}+$ Valve, $\mathrm{n}=15)$ or all types of surgery altogether (All, $n=47$ ). Data are mean \pm standard error of the mean of a total of 47 patients. 


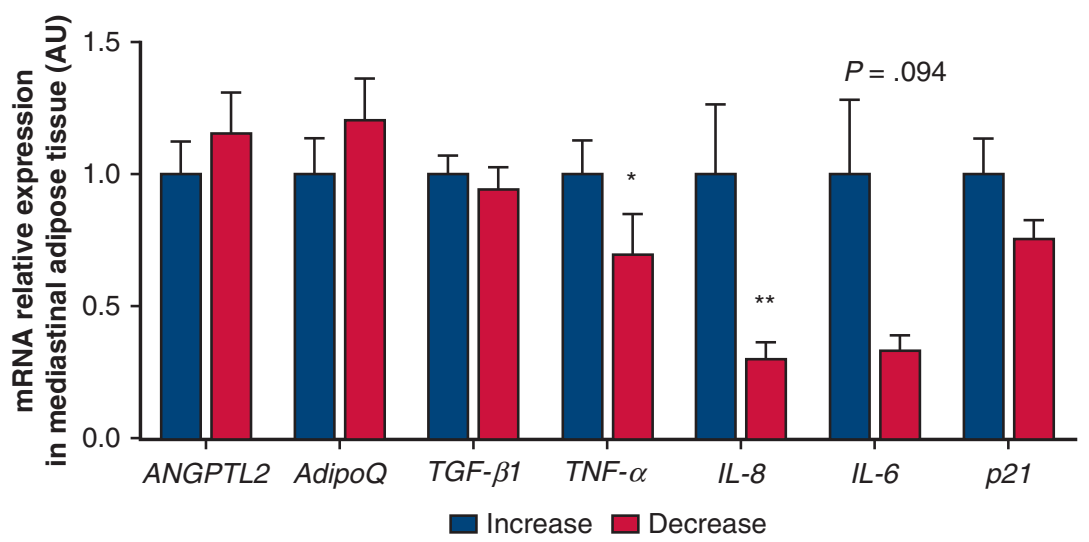

A

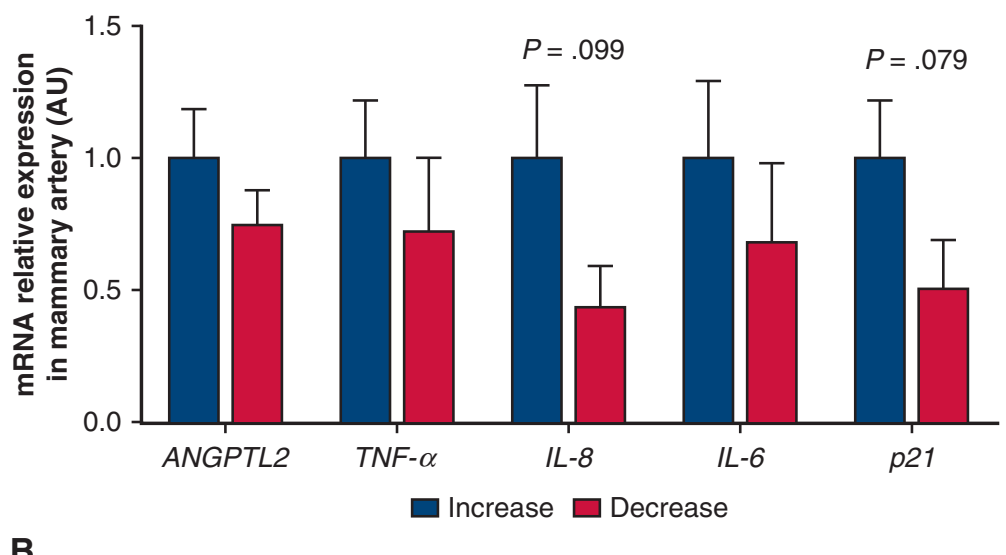

FIGURE E5. A, Gene expression in mediastinal adipose tissue in patients in whom plasma angiopoietin-like 2 (ANGPTL2) levels either decreased ( $\mathrm{n}=19)$ or increased $(\mathrm{n}=25)$. B, Gene expression in internal mammary artery fragments in patients in whom plasma ANGPTL2 levels either decreased $(\mathrm{n}=10)$ or increased $(\mathrm{n}=13)$. $A U$, Arbitrary units; Adipo $Q$, adiponectin; $T G F$, transforming growth factor; $T N F$, tumor necrosis factor; $I L$, interleukin; $p 21$, cyclindependent kinase inhibitor 1 . 
TABLE E1. Comparison of operative parameters in the 2 groups of patients with positive (INCREASED group) or negative (DECREASED group) $\triangle$ ANGPTL2

\begin{tabular}{|c|c|c|c|c|c|c|c|c|c|}
\hline & \multicolumn{3}{|c|}{$\operatorname{CABG}(n=16)$} & \multicolumn{3}{|c|}{ CABG and valve $(n=15)$} & \multicolumn{3}{|c|}{ Valve $(n=16)$} \\
\hline & $\begin{array}{c}\text { DECREASED } \\
(n=7)\end{array}$ & $\begin{array}{c}\text { INCREASED } \\
(\mathbf{n}=\mathbf{9})\end{array}$ & $P$ value & $\begin{array}{c}\text { DECREASED } \\
(n=6)\end{array}$ & $\begin{array}{c}\text { INCREASED } \\
(\mathbf{n}=\mathbf{9})\end{array}$ & $P$ value & $\begin{array}{c}\text { DECREASED } \\
(\mathrm{n}=8)\end{array}$ & $\begin{array}{c}\text { INCREASED } \\
(\mathbf{n}=\mathbf{8})\end{array}$ & $P$ value \\
\hline Ao-clamp, minutes & $35.9 \pm 18.7$ & $49.6 \pm 17.4$ & .153 & $85.8 \pm 13.0$ & $71.2 \pm 24.2$ & .201 & $57.9 \pm 14.8$ & $60.4 \pm 9.8$ & .696 \\
\hline $\mathrm{CPB}$, minutes & $55.9 \pm 26.6$ & $64.2 \pm 12.9$ & .420 & $104.7 \pm 12.0$ & $85.7 \pm 30.5$ & .174 & $69.1 \pm 15.7$ & $73.9 \pm 11.6$ & .503 \\
\hline Grafts, $n$ & $2.9 \pm 0.9$ & $3.1 \pm 0.8$ & .556 & $2.3 \pm 0.5$ & $1.9 \pm 0.9$ & .308 & & & \\
\hline Simple & 0 & 0 & & 1 & 4 & .264 & & & \\
\hline Double & 3 & 2 & .377 & 3 & 2 & .264 & & & \\
\hline Triple & 2 & 4 & .515 & 2 & 3 & 1.00 & & & \\
\hline Quadruple & 2 & 3 & .834 & 0 & 0 & & & & \\
\hline IMA, n & $1.3 \pm 0.5$ & $1.2 \pm 0.4$ & .789 & $1.0 \pm 0.6$ & $0.7 \pm 0.7$ & .369 & & & \\
\hline $\mathrm{SV}, \mathrm{n}$ & $1.6 \pm 0.8$ & $1.9 \pm 0.9$ & .481 & $1.3 \pm 0.8$ & $1.2 \pm 0.4$ & .737 & & & \\
\hline $\mathrm{ICU}, \mathrm{d}$ & $2.0 \pm 1.4$ & $1.1 \pm 0.3$ & .087 & $2.7 \pm 1.0$ & $3.9 \pm 3.3$ & .400 & $2.1 \pm 1.8$ & $2.8 \pm 1.8$ & .503 \\
\hline Hosp, d & $9.9 \pm 5.5$ & $9.1 \pm 3.8$ & .751 & $11.2 \pm 5.0$ & $8.4 \pm 3.5$ & .234 & $7.8 \pm 2.6$ & $8.0 \pm 4.1$ & .886 \\
\hline
\end{tabular}

Data are mean \pm standard deviation of $\mathrm{n}$ patients. Unpaired t-test and Chi-squared test were used. $C A B G$, Coronary artery bypass grafting; $A o$-clamp, duration of aorta clamping; $C P B$, duration of cardiopulmonary bypass; $I M A$, internal mammary artery; $S V$, saphenous vein; $I C U$, intensive care unit; Hosp, hospitalization.

TABLE E2. Primer sequences used in quantitative reverse transcription-polymerase chain reaction

\begin{tabular}{llc}
\hline Target gene & \multicolumn{1}{c}{ Forward } & Reverse \\
\hline$A N G P T L 2$ & CCCCAACACCTTCCACTAAG & AACAGAATCCAGCATCCCG \\
$A D I P O Q$ & ACTGCAGTCTGTGGTTCTGA & TAGAACAGCTCCCAGCAACA \\
$T G F-\beta 1$ & CCTTTCCTGCTTCTCATGGC & TCCGTGGAGCTGAAGCAATA \\
$T N F-\alpha$ & CTCTTCTGCCTGCTGCACTT & CTCTCAGCTCCACGCCATTG \\
$I L-8$ & CTCTTGGCAGCCTTCCTGAT & TTCTGTGTTGGCGCAGTGTG \\
$I L-6$ & GACAGCCACTCACCTCTTCA & CACCAGGCAAGTCTCCTCAT \\
$p 21$ & GGACCTGTCACTGTCTTGTA & CCTCTTGGAGAAGATCAGCCG \\
$G A P D H$ & AATCCCATCACCATCTTCCA & AAATGAGCCCCAGCCTTC \\
\hline
\end{tabular}

ANGPTL2, Angiopoietin-like 2; $A D I P O Q$, adiponectin; $T G F$, transforming growth factor; $T N F$, tumor necrosis factor; $I L$, interleukin; $p 21$, cyclin-dependent kinase inhibitor 1 ; $G A P D H$, glyceraldehyde-3-Phosphate Dehydrogenase. 
TABLE E3. Correlations between plasma ANGPTL2 levels at baseline and inflammatory and senescent markers in mediastinal adipose tissue and internal mammary artery segments

\begin{tabular}{cccc}
\hline Samples & $\begin{array}{c}\text { Gene expression } \\
\text { versus basal plasma } \\
\text { ANGPTL2 level }\end{array}$ & $\boldsymbol{r}$ & $\boldsymbol{P}$ value \\
\hline Mediastinal adipose tissue & $A N G P T L 2$ & 0.173 & .261 \\
& $T N F-\alpha$ & -0.005 & .975 \\
\hline Mammary artery segments & $I L-8$ & -0.244 & .157 \\
& $I L-6$ & -0.004 & .983 \\
\hline & ANGPTL2 & -0.060 & .789 \\
\hline & $T N F-\alpha$ & -0.262 & .251 \\
& $I L-8$ & -0.375 & .078 \\
\hline & $I L-6$ & -0.221 & .336 \\
\hline & $p 21$ & -0.321 & .145 \\
\hline
\end{tabular}

Data are mean \pm standard error of the mean of 44 patients in mediastinal adipose tissue and 23 patients in mammary artery fragments. ANGPTL2, Angiopoietin-like 2; TNF, tumor necrosis factor; IL, interleukin; p21, cyclin-dependent kinase inhibitor 1.

TABLE E4. Correlations between plasma hs-CRP levels at baseline and inflammatory and senescent markers in mediastinal adipose tissue and internal mammary artery segments

\begin{tabular}{cccc}
\hline Samples & $\begin{array}{c}\text { Gene expression } \\
\text { versus basal plasma } \\
\text { hs-CRP level }\end{array}$ & $\boldsymbol{r}$ & $\boldsymbol{P}$ value \\
\hline Mediastinal adipose tissue & $A N G P T L 2$ & -0.154 & .325 \\
& $T N F-\alpha$ & 0.365 & $\mathbf{. 0 2 4}$ \\
\hline Mammary artery segments & $I L-8$ & 0.225 & .200 \\
& $I L-6$ & 0.159 & .362 \\
\hline & $p 21$ & 0.246 & .137 \\
& $A N G P T L 2$ & -0.003 & .988 \\
\hline & $T N F-\alpha$ & -0.033 & .887 \\
& $I L-8$ & -0.220 & .313 \\
\hline & $I L-6$ & -0.156 & .500 \\
\hline & $p 21$ & -0.177 & .431 \\
\hline
\end{tabular}

Data are mean \pm standard error of the mean of 44 patients in mediastinal adipose tissue and 23 patients in mammary artery fragments. $P<.05$ are indicated in bold. hs-CRP, High-sensitivity C-reactive protein; ANGPTL2, angiopoietin-like 2; TNF, tumor necrosis factor; IL, interleukin; p21, cyclin-dependent kinase inhibitor 1. 